\title{
Environmental impact of novel thermal and non-thermal technologies in food processing
}

\author{
R.N. Pereira *, A.A. Vicente \\ IBB - Institute for Biotechnology and Bioengineering, Centre for Biological Engineering, University of Minho, Campus of Gualtar, 4710-057 Braga, Portugal
}

\section{A R T I C L E I N F O}

\section{Article history:}

Received 1 May 2009

Accepted 8 September 2009

\section{Keywords:}

Novel food processing technologies

Environmental impact

Energy efficiency

Water savings

\begin{abstract}
A B S T R A C T
During the last 25 years, consumer demands for more convenient and varied food products have grown exponentially, together with the need for faster production rates, improved quality and extension in shelf life. These requests together with the severity of the traditional food processing technologies were driving forces for improvements in existing technologies and for the development of new food preservation technologies. Therefore, many technological developments have been directed towards unit operations such as pasteurization, sterilization, cooking and drying, and currently the new technological approaches for food preservation are serious candidates to replace the traditional well-established preservation processes. The aim of this review is to discuss the environmental impact that some of the most promising novel food preservation technologies may represent in terms of energy efficiency, water savings and reduced emissions. The emergence of novel thermal and non-thermal technologies allows producing high quality products with improvements in terms of heating efficiency and, consequently, in energy savings. Most of these technologies are locally clean processes and therefore appear to be more environmentfriendly, having less environmental impact than the traditional ones. Novel processing technologies are increasingly attracting the attention of food processors once they can provide food products with improved quality and a reduced environmental footprint, while reducing processing costs and improving the added-value of the products.
\end{abstract}

(c) 2009 Elsevier Ltd. All rights reserved.

\section{Introduction}

Food preservation whilst ensuring its safety and quality has been a prime goal of food processors. The use of heat through thermal processing operations, which among others includes pasteurization, sterilization, drying and evaporation, is still a common practice of the food industries in order to guarantee the microbiological safety of their products. These traditional heating methods rely essentially on the generation of heat outside the product to be heated, by combustion of fuels or by an electric resistive heater, and its transference into the product through conduction and convection mechanisms. However, these ways of processing are still limited due to considerable losses of heat on the surfaces of the equipment and installations, reduction of heat transfer efficiency and thermal damage by overheating, due to the time required to conduct sufficient heat into the thermal centre of foods. Some of these effects are being attenuated through developments on control and monitoring systems for food processing plants, intelligent design of equipments and installations, heat recycling and isolation measures, but this also represents high additional financial costs. Therefore the efforts of processors together with academic circles

\footnotetext{
* Corresponding author. Tel.: +351253604 400; fax: +351253678986

E-mail address: rpereira@deb.uminho.pt (R.N. Pereira).
}

in attending consumer demands for high quality food and dealing with raising economic standards, and nowadays particularly with ecological concerns, has triggered the development of emergent technological approaches for food processing. Recently, electromagnetic technologies in food processing have gained increased industrial interest and have potential to replace, at least partially, the traditional well-established preservation processes (Vicente \& Castro, 2007). Ohmic heating and dielectric heating, which includes radio frequency (RF) and microwave (MW) heating, are promising alternatives to conventional methods of heat processing. These novel thermal technologies are regarded as volumetric forms of heating in which thermal energy is generated directly inside the food. This common pattern of heat generation allows overcoming excessive cooking times and consequently may have direct implications in terms of both energetic and heating efficiency. In the last decade, non-thermal technologies for inactivating microorganisms have also been developed in response to the worldwide interest for more fresh and natural food products. Novel non-thermal technologies such as ultrasounds (US), high pressure processing (HPP) pulsed electric fields (PEF) and pulsed light treatment (PL), among others, have the ability to inactivate microorganisms at near-ambient temperatures, avoiding thermal degradation of the food components, and consequently preserving the sensory and nutritional quality of the fresh-like food products. Some of the effects of these 
novel thermal and non-thermal technologies on the preservation and quality of several food products have been reviewed and constitute valuable information for regulatory approval and as backup for investment decisions from food processors. In order to achieve their full potential for industrial implementation and commercial exploitation, issues related with the environmental impact, such as e.g. wastewater and gas emissions, the conservation of nonrenewable resources and energy consumption are increasingly attracting the attention of the food processors since they can represent significant reductions of the processing costs. The purpose of this text is to provide a general perspective of the so-called novel thermal and non-thermal processing technologies currently available in connection with their actual and foreseen environmental impact once implemented by the food industry.

\section{Novel thermal processing technologies}

\subsection{Dielectric heating}

\subsubsection{Radio frequency (RF) and microwave (MW) heating}

Dielectric heating implies the interaction between an electromagnetic alternating field and the dipoles and ionic charges contained within a food product that enables the volumetric heating of the product. RF and MW systems operate by the same principle, forcing polar molecules, such as water, and ionic species to constantly realign themselves by reversing an electric field around the food product. This molecular movement is extremely fast due to the high frequency of the field, which in RF can range from 1 to $300 \mathrm{MHz}$ and in MW from 300 to $3000 \mathrm{MHz}$. The molecular friction produced by dipole rotation and by the migration of ionic species under the influence of the oscillating electromagnetic field, generates heat inside the food by energy dissipation. RF and MW are considered non-ionizing radiation because they have insufficient energy $(<10 \mathrm{eV})$ to ionize atoms (Piyasena, Dussault, Koutchma, Ramaswamy, \& Awuah, 2003). However, since RF and MW are both within the radar range, the frequency bands that can be used for applications other than communications are limited by Electromagnetic Compatibility (EMC) regulations. There are a relatively small number of internationally agreed frequency bands known as Industrial and Scientific and Medical (ISM) bands that can be used for dielectric heating in food processing (see Table 1). The rate of heat generation per unit volume at a particular location within a food material during MW and RF heating $(\dot{U})$ can be characterized by Eq. (1) (Buffler, 1993; Rowley, 2001):

$\stackrel{\cup}{U}=2 \pi \cdot f \cdot \varepsilon_{0} \cdot \varepsilon^{\prime \prime} \cdot|\nabla V|^{2}$

where $|\nabla V|^{2}$ is the strength of the electric field of the wave at that location, $f$ is the microwave/RF frequency, $\varepsilon_{0}$ is the permittivity of free space and $\varepsilon^{\prime \prime}$ is the dielectric loss factor representing the food materials ability to absorb the wave. Despite that RF and MW are both capable of offering rapid, non-contact volumetric heating, they can be distinguished itself by the way that electric field is generated

Table 1

Frequency allocations for industrial, scientific and medical uses.

\begin{tabular}{ll}
\hline Dielectric heating & Frequency $(\mathrm{MHz})$ \\
\hline Microwave & $8.960 \times 10^{2}(\mathrm{UK})$ or $9.150 \times 10^{2}$ (EUA) \\
& $2.450 \times 10^{3}$ \\
& $5.800 \times 10^{3}$ \\
& $2.4125 \times 10^{4}$ \\
& $1.356 \times 10$ \\
& $2.712 \times 10$ \\
Radio frequency & $4.680 \times 10$
\end{tabular}

Adapted from Leadley (2008). and depth of electromagnetic waves. Wavelength at the RF frequencies is up to 360 times greater than the wavelength corresponding to the two frequency values commonly used for $\mathrm{MW}(915 \mathrm{MHz}$ and $2450 \mathrm{MHz}$ ), which allows RF energy to penetrate foods more deeply than MW (Wang, Wig, \& Halleberg, 2003b). Since heating applications in food processing require a uniform temperature in the food being heated, achievement of this using MW can be a difficult task that makes this technology profitable only for small sized foods (Marra, Lyng, Romano, \& McKenna, 2007). In RF heating, the electrical field is generated in a directional manner between a pair of capacitor plates; the food material to be heated is placed between the two plates, where it plays the role of a dielectric. Microwaves are primarily a radiation phenomenon that usually takes place in an enclosed cavity, or in close vicinity to a waveguide applicator, where the electrical component of the microwave field approaches the food product from all directions (Leadley, 2008; Piyasena et al., 2003).

The promise of rapid and volumetric heating has called the attention of food industry for the potential use of dielectric systems. Industrial and experimental applications of MW for food preservation, among others include sterilization and pasteurization of ready to eat meals, continuous pasteurization of milk and pasta drying (Decareau, 1985; Leadley, 2008; Rosenberg \& Bögl, 1987). RF systems could be particularly suitable for heat processing of cured whole meat products such as ham (Bengtsson \& Green, 1970; McKenna, Lyng, Brunton, \& Shirsat, 2006; Ryynänen, 1995), while, RF drying of foods ingredients (e.g. herbs, spices, vegetables), snack foods (Mermelstein, 1998), potato products and pasta products are well established applications (Rowley, 2001). Radio frequency heating systems for the purpose of food pasteurization or sterilization are still being investigated due to the capability for rapid and uniform heating, and it is anticipated that RF will be capable of producing shelf-stable food with higher quality for civilian and military use (Wang, Wig, \& Hallberg, 2003a). However, before fully commercial implementation of RF technology for pasteurization and sterilization of packaged foods, potential problems such as dielectric arcing and thermal runaway heating need to be addressed (Zhao, 2006). The knowledge of dielectric properties of foods to be heated is a key factor for an effective RF and MW heating. Much in the same way, the factors that influence dielectric properties of the foods during heating, such as mass, shape, water content, chemical composition, temperature and frequency of treatment, must be fully understood for further development and industrial setup of dielectric heating systems in food processing (Zhao, 2006).

\subsection{Ohmic heating}

Ohmic heating $(\mathrm{OH})$, also called Joule heating, electrical resistance heating or electroconductive heating, is based on the principle that most food products have the ability to resist to the passage of an electrical current. Heating occurs when an alternating electrical current is passed through a food resulting in the internal generation of heat, due to the electrical resistance of the food (de Alwis \& Fryer, 1990). Once OH relies on direct ohmic conduction losses in a medium it requires the direct contact between the electrodes and the food product to be heated. The energy generation rate of food under ohmic heating can be calculated by Eq. 2 (Sastry \& Palaniappan, 1992):

$\stackrel{\circ}{U}=|\nabla V|^{2} \sigma$

where energy generation $\stackrel{\circ}{U}$ for heating is achieved through the application of a voltage distribution $|\nabla V|$ to a food with a given electrical conductivity, $\sigma$, which is the critical property affecting energy generation and shows a remarkable dependence on temperature 
(Vicente \& Castro, 2007). For most of the solid foods $\sigma$ increases sharply with temperature and the relationship between $\sigma$ and temperature becomes linear with increasing field strength values (Sastry \& Palaniappan, 1992). For liquid foods, $\sigma$ always displays a linear relationship with temperature if non-conductive constituents are absent (Vicente \& Castro, 2007). Depending on the value of $\sigma$ in some products, the particulates could heat preferentially to the carrier fluid, if needed, however, the ionic content of products to be heated can be altered (e.g. addition of electrolytes, such as $\mathrm{NaCl}$ ) to improve the effectiveness of heating. If the values of $\sigma$ are similar for all the components of the product then it heats uniformly. In addition to $\sigma$ other parameters such as particle orientation, geometry, size and concentration affect the $\mathrm{OH}$ rate: when more than one phase is present these parameters can exert their influence via the effective conductivity of the mixture ( $\left.\sigma_{\text {eff }}\right)$, which is the case of particle size and concentration, or they can directly influence the heating rate of the different constituents, which is the case of particle orientation and geometry (Vicente, Teixeira, \& Castro, 2006). In short, $\mathrm{OH}$ technology is distinguished from other electrical heating methods by the presence of electrodes contacting the foods (in microwave and inductive heating electrodes are absent), the frequency applied (unrestricted, except for the specially assigned radio or microwave frequency range), and the waveform (also unrestricted, although typically sinusoidal) (Vicente \& Castro, 2007). The major benefits claimed for ohmic heating technology are as follows:

- Temperature required for HTST processes can be achieved very quickly.

- Suitable for continuous processing without heat transfer surfaces.

- Uniform heating of liquids with faster heating rates.

- Reduced problems of surface fouling or over heating of the product compared to conventional heating.

- Fresher-tasting, higher quality products than with alternate heat preservation techniques.

- No residual heat transfer after the current is shut off, and very low heat losses.

- Useful in pre-heating products before canning.

- Low maintenance costs (no moving parts) and high energy conversion efficiencies.

- Environmentally-friendly system.

Potential industrial applications of $\mathrm{OH}$ are very wide and include blanching, drying, evaporation, dehydration, fermentation (Cho, Yousef, \& Sastry, 1996). Due to its extremely rapid heating rates, ohmic heating technology enables higher pasteurization temperatures to be applied, with the consequent increase in refrigerated shelf life, without inducing coagulation or excessive denaturation of the constituent proteins (Parrott, 1992). For all these reasons the focus of $\mathrm{OH}$ is being currently addressed to thermal processing operations for food preservation once this technology can be accomplished in a continuous in-line heater for cooking and sterilization. $\mathrm{OH}$ is particularly suitable for the processing of viscous, liquid foods (Icier \& Ilicali, 2005b) and foods containing particles. Several research works were already developed in order to contribute to the validation of ohmic heating technology for use in applications such as the processing of a low-acid particulate product in a can (Ramaswamy, Balasubramaniam \& Sastry, 2005), meat cooking (de Halleux, Piette, Buteau, \& Dostie, 2005) stabilization of baby foods (Icier \& Ilicali, 2005a), and pasteurization of milk (Pereira, Martins, \& Vicente, 2008). Commercial ohmic heating systems are now available from a number of suppliers including Invesys APV (Crawley, UK), Raztek Corp. (Sunnyvale, CA, USA) and Emmpiemme SRL (Piacenza, Italy) (Leadley, 2008). As an example, a list of industrial ohmic heating plants installed by Emmepiemme SRL is shown in Table 2.
Table 2

Industrial ohmic heating plants installed by Emmepiemme for thermal processing of foods.

\begin{tabular}{lllc}
\hline Country & $\begin{array}{l}\text { Year } \\
\text { (installation) }\end{array}$ & Product & $\begin{array}{l}\text { Heat } \\
\text { power } \\
(\mathrm{kW})\end{array}$ \\
\hline Italy & 1994 & Tomato sauces and pastes & \\
Greece & 1998 & Peach and apricot slice and dice & 50 \\
Italy & 2000 & Diced pears and apples & 150 \\
Italy & 2001 & Low-acid vegetables purées & 150 \\
Mexico & 2002 & Strawberries & 100 \\
France & 2002 & Fruit preparation & 250 \\
France & 2003 & Processing line for meat recipes & 100 \\
Italy & 2004 & $\begin{array}{l}\text { Plum peeled tomato and tomato } \\
\text { dices* }\end{array}$ & 50 \\
Italy & 2005 & Vegetables sauces $^{*}$ & 60 \\
\hline
\end{tabular}

Adapted from Leadley (2008)

Aseptic process and filling.

\section{Novel non-thermal processing technologies}

The term 'non-thermal processing' is often used to designate technologies that are effective at ambient or sublethal temperatures. High hydrostatic pressure, pulsed electric fields, high-intensity ultrasound, ultraviolet light, pulsed light, ionizing radiation and oscillating magnetic fields have the ability to inactivate microorganisms to varying degrees (Butz \& Tauscher, 2002). Some of these treatments may involve heat due to the generation of internal energy (e.g. adiabatic heating and resistive heating during HHP and PEF, respectively), however, they are classified as non-thermal once, contrarily to thermal processing technologies, they can eliminate the use of high temperatures to kill the microorganisms, avoiding the deleterious effects of heat on flavor, color and nutritive value of foods.

These novel technologies are still struggling with impairments to their full industrial application. For example, irradiation has a high potential and is probably one of the most versatile among the food preservation technologies. However, its development and commercialization has been hampered in the past by unfavourable public perceptions (Resurreccion, Galvez, Fletcher, \& Misra, 1995). Ultraviolet (UV) radiation is an established disinfection alternative used to produce drinking water. More than 500 UV plants supplying drinking water operate in North America, and in Europe more than 2000 plants use this technology as a common disinfection technique for drinking water supplies. The benefits of UV treatment in comparison to other methods of disinfection are very clear: no chemicals are used; it is a non-heat-related process; lesser changes in color, flavor, odor, or $\mathrm{pH}$; and no residuals are left in the fluid stream. However, a potential problem of using short-wave UV light is that it can damage human eyes, and prolonged exposure can cause burns and skin cancer in humans (Bintsis, Litopoulou-Tzanetaki, \& Robinson, 2000; Shama, 1999), which is a concern especially among industry workers. Pulsed Light is also considered an emerging, non-thermal technology capable of reducing the microbial population on the surface of foods and food contact materials by using short and intense pulses of light in the Ultraviolet Near Infrared (UV-NIR) range. PL systems have relatively low operation costs and do not significantly contribute negatively to the environmental impact of the processes where it is included because it has the potential to eliminate microorganisms without the need for chemicals. Further, it does not produce volatile organic compounds (VOC) and generates only reduced amounts of solids wastes. However, the poor penetrating power of light (requires transparency and surface smoothness of the product to be treated) and high investment costs ( $€ 300,000$ 800,000 ) are currently limiting PL applications. The most 
interesting application of PL systems could be in sterilizing films of packaging material as an alternative to hydrogen peroxide (Palmieri and Cacace, 2005).

Extensive research is being conducted on the effects that other technologies such as ultrasound and magnetic fields may have on biological systems. Data on these subjects are still scarce and, therefore, further research should be carried out to extend the present knowledge.

The most extensively researched and promising non-thermal processes for preservation of foods appear to be pulsed electric fields (PEF) and high hydrostatic pressure (HHP) (Ross, Griffiths, Mittal, \& Deeth, 2003), which are being commercially applied mostly for the processing of juices and other fruit-derived products (Jia, Zhang, \& Min, 1999; Leistner \& Gould, 2002; Mermelstein, 1997; Qiu, Sharma, Tuhela, Jia, \& Zhang, 1998).

\subsection{Pulsed electric fields (PEF)}

PEF offers the ability to inactivate microorganisms with minimal effects on the nutritional, flavor and functional characteristics of food products due to the absence of heat. PEF technology is based on the application of pulses of high voltage (typically 20$80 \mathrm{kV} / \mathrm{cm}$ ) delivered to the product placed between a set pair of electrodes that confine the treatment gap of the PEF chamber. The large field intensities are achieved through storing a large amount of energy in a capacitor bank (a series of capacitors) from a direct current power supply, which is then discharged in the form of high voltage pulses (Zhang, Barbosa-Cánovas, \& Swanson, 1995). The pulse caused by the discharge of electrical energy from the capacitor is allowed to flow through the food material for an extremely short period of time $(1-100 \mu \mathrm{s})$ and can be conducted at moderate temperatures for less than $1 \mathrm{~s}$ (Deeth, Datta, Ross, \& Dam, 2007). When food is subjected to the electrical high-intensity pulses several events, such as resistance heating (Sastry \& Barach, 1995), electrolysis (Hulsheger \& Niemann, 1980) and disruption of cell membranes (Sitzmann, 1995), can occur contributing to the inactivation of microorganisms. In fact, several theories exist for the destruction of bacterial cells by PEF, but they commonly describe damage on the cell membrane (electroporation) which affects its functioning and may lead to cell death (Deeth et al., 2007; Sale \& Hamilton, 1968). PEF technology is mainly intended for preservation of pumpable fluid or semi-fluid foods (Qin, Pothakamury, Barbosa-Cánovas, \& Swanson, 1996). In particular it could be used to improve the shelf-life of milk (Craven et al., 2008; Sampedro, Rodrigo, Martinez, Rodrigo, \& Barbosa-Cánovas, 2005), green pea soups (Vega-Mercado, Martin-Belloso, Chang, BarbosaCánovas, \& Swanson, 1996), liquid whole eggs (Barbosa-Cánovas, 2001; Ma, Chang, \& Barbosa-Cánovas, 1997) and fruit juices (Heinz, Toepfl, \& Knorr, 2002; Hodgins, Mittal, \& Griffiths, 2002). In fact, the adoption of PEF for commercial non-thermal pasteurization of fruit juices has been first implemented by Genesis Juices, Oregon, USA (Clark, 2006). A combination of mild heat and PEF might also be helpful to achieve sufficient enzyme inactivation to avoid the necessity of refrigerated storage. When operating at high treatment temperatures and making use of synergetic heat effects, PEF energy input might be reduced close to the amount required for conventional thermal pasteurization, assuming $95 \%$ of heat recovery (Toepfl, Mathys, Heinz, \& Knorr, 2006). Although the study of PEF technology has been focused on its ability to inactivate microorganisms in liquid food products at low temperatures, some other applications in the food industry have been explored as well, such as the enhancement of drying efficiency and decontamination of liquid waste (Barbosa-Cánovas \& Sepúlveda, 2005).

The lack of understanding of the factors that can affect the efficacy of PEF-treatment, such as proper processing conditions and design of equipment, type of microorganism, suitability and prop- erties of the treated food (Deeth et al., 2007), are currently limiting the validation of this technology for commercial application.

\subsection{High hydrostatic pressure (HHP)}

The application of HHP on foodstuffs is currently a subject of major interest for both food preservation and food preparation (Lopez-Fandiño, Carrascosa, \& Olano, 1996) once it inactivates vegetative microorganisms by using pressure rather than heat to achieve pasteurization. Food processing by high hydrostatic pressure has been reviewed by several authors, giving particular attention to microbiological, (bio)chemical, technological, environmental and energetic aspects (Barbosa-Cánovas, Palou, \& Swanson, 1997; Butz, Funtenberger, Haberditzl, \& Tauscher, 1996; Cheftel, 1995; Cheftel \& Culioli, 1997; Galazka \& Ledward, 1995; Hendrickx, Ludikhuyze, Van den Broeck, \& Weemaes, 1998; Heremans, 1995; Ludikhuyze, Van Loey, Indrawati, \& Hendrickx, 2003; Messens, Van Camp, \& Huyghebaert, 1997; Meyer, Cooper, Knorr, \& Lelieveld, 2000; Mozhaev, Heremans, Frank, Masson, \& Balny, 1994; Patterson, 2005; San Martin, Barbosa-Canovas, \& Swanson, 2002; Toepfl et al., 2006). The high pressure treatment of foods involves subjecting food materials to pressures that generally can range from of 100 to $1000 \mathrm{MPa}$. In agreement with the isostatic principle, during HHP pressure is applied uniformly and instantaneously through a food material (with or without packaging), independently of its mass, shape and composition. Under pressure, biomolecules obey the Le Chatelier-Braun principle and reactions that result in reduced volume will be promoted. Such reactions affect the structure of large molecules (whose tertiary structure is important for functionality), such as proteins. HPP causes a partial unfolding of proteins that can promote covalent and non-covalent interactions during and upon release of pressure, thus triggering their denaturation. This results in the inactivation of microorganisms and enzymes (Hendrickx et al., 1998) and can also promote changes in the rheological properties of the food products (Ahmed, Ramaswamy, Alli, \& Ngadi, 2003). On the other hand, small molecules that have little secondary, tertiary and quaternary structures, such as amino acids, vitamins and flavor and aroma components contributing to the sensory and nutritional quality of food, remain unaffected (Balci \& Wilbey, 1999; Cheftel, 1991). Process temperature during HHP can be specified from below $0{ }^{\circ} \mathrm{C}$ (to minimize any effects of adiabatic heat) to above $100{ }^{\circ} \mathrm{C}$ and exposure times can range from a millisecond pulse to a treatment time of over $20 \mathrm{~min}$. In contrast to thermal processing, economic requirements for throughput may limit exposure times of treatment to less than 20 min (Food \& Nutrition, 2000). Overall, this technology offers several advantages for food preservation: (1) homogeneity of treatment due to the fact that pressure is uniformly applied around and throughout the food product; (2) minimal heat impact; (3) shelflives similar to thermal pasteurization, while maintaining the natural food quality parameters (nutrients and sensorial preservation); (4) small amount of energy needed to compress a solid or liquid to $500 \mathrm{MPa}$ as compared to heating to $100{ }^{\circ} \mathrm{C}$, (Tewari, 2007). HHP cold pasteurization technology is gathering applicability throughout the world in the processing of a variety of product categories. HPP has already become a commercially implemented technology, spreading from its origins in Japan, followed by USA and now in Europe, with worldwide take-up increasing almost exponentially since 2000 . In 2005 it was estimated that there were around 82 commercial-scale high pressure food processing systems in use worldwide. Examples of HHP processed products established in the industrial sector include cooked meats, seafood and fish, vegetables and fruit juices (Norton \& Sun, 2008). Apart from consumer benefits and reduction of energy costs, a key advantage of high pressure processing is its applicability to packaged foods, making obsolete the efforts to prevent recontamination 
or the use of aseptic filling processes (Toepfl et al., 2006). Currently, foods with a high acid content are particularly good candidates for HPP technology, contrary to low acid, shelf-stable products which are not commercially available yet because of the limitations in killing spores (Ramaswamy, Balasubramaniam \& Kaletun, 2005). Bacterial spores are very resistant to commercially achievable pressures and, as a result, products that are currently on the market are chilled, and many are high acid or contain additional preservation hurdles such as the presence of antimicrobial compounds (Garriga, Aymerich, Costa, Monfort \& Hugas, 2002). In addition, there is a need for further research to determine the effects of high pressure on the physicochemical and mechanical properties of packaging films (Leadley, 2008).

\section{Environmental impact}

The energy consumption and energy savings in the food industry have been in focus for the last 30 years. This is due in part to comprehensive automation of production processes and particularly by the increasing demand for food safety. The higher levels of hygiene consecutively established as goals subsequently lead to a larger consumption of cold and hot water as well as an increased number of cleaning cycles in production (Dalsgaard \& Abbots, 2003). This has dramatically increased the environmental footprint of the food industry. Thermal preservation operations in the food industry, such as cooking, pasteurization, sterilization and drying involve the consumption of a cocktail of energy types. Generally, the principal type of energy used for traditional thermal processing is fossil fuel, whereas electricity is mainly used for refrigeration and generation of mechanical power for pumps (Dalsgaard \& Abbots, 2003). A common approach to the pasteurization of beverages (such as milk, beer and fruit juices), is the use of heat exchangers (plate, tubular, shell and spiral heat exchangers), which are capable of handling two or more fluid streams in a single unit. In the basic process, liquids flow continuously through a heat exchanger, where they are heated for the required residence time to kill pathogens. During thermal treatment, the food product and the heating medium are separated by heat-conducting barriers and heat is transferred to the product by conduction and convection. Direct heating methods such as steam injection and steam infusion are also used for thermal processing, particularly highly viscous fluids. These methods offer high heating rates, however, the resulting dilution may not be a desirable effect. The distribution of energy in the food and beverage industries in Denmark in 2002 (Table 3) clearly shows that the majority of the energy input in food processing is used for thermal purposes, such as heating, drying, evaporation and frying. This trend is still valid until the present moment.

The novel thermal and non-thermal technologies for food processing already mentioned (RF, MW and $\mathrm{OH}$ heating, PEF and HHP) are being developed and evaluated continuously, many of which can provide not only energy savings, but also water savings, increased reliability, reduced emissions, higher product quality, improved productivity (Masanet, Worrell, Graus, \& Galitsky, 2008), and consequently, less impact on the environment. However, for many of the emerging technologies, that kind of informa-

Table 3

Energy consumption in food and beverage industries in Denmark in 2002.

\begin{tabular}{ll}
\hline Consumption & Energy (TJ/Year) \\
\hline Power & 30,700 \\
Heating & 104,500 \\
Total & 135,200 \\
\hline
\end{tabular}

Adapted from Dalsgaard and Abbots (2003). tion is still scarce or nonexistent in the published literature. Actual technology performance will depend on the facility, the application of the technology, and the existing production equipment with which the new technology is integrated (Masanet et al., 2008).

\subsection{Energy savings}

A recent study (Lung, Masanet, \& McKane, 2006) provided estimated information on the potential energy savings of PEF and dielectric drying systems compared to existing technologies. Orange juice and cookies manufacturing were chosen as the representative target industrial sectors for the analysis of PEF pasteurization and RF drying, respectively. Concerning PEF pasteurization, the natural gas savings were estimated at $100 \%$, since thermal processing is eliminated. The electricity savings of PEF can be up to $18 \%$, based on the assumed electricity consumption range of the base technology. Concerning RF drying of cookies the estimated natural gas savings ranged from 73.8 to $147.7 \mathrm{TJ}$ per year, however, these savings were masked by the increase in electricity consumption, necessary to power the RF drying unit. Depending on the natural gas consumption of the base tunnel oven, the primary energy savings of RF drying can range from 0 to $73.8 \mathrm{TJ}$ per year.

On the other hand, in accordance with Toepfl (2006), the preservation of liquid media by PEF was shown to cause operation costs in the range of 1-2 $€$-cents per liter, about 10 -fold higher than those needed for conventional thermal processing. However, the impact of pulse energy dissipation and the simultaneous resistive heating of the suspending medium have to be taken into account, since the medium temperature will increase and energy efficient PEF processing requires taking advantage of synergistic effects of mild heat (Toepfl et al., 2006). The combined synergistic effects of mild treatment temperatures and PEF can provide a shorter treatment time with energy recovery and an energy requirement of less than $40 \mathrm{~kJ} / \mathrm{kg}$ for a reduction of $6 \log$ cycles of Escherichia coli. In this example, an energy input of $40 \mathrm{~kJ} / \mathrm{kg}$ will result in a temperature increase of $11^{\circ} \mathrm{C}$ in the case of orange juice, showing that with a maximum temperature of $66^{\circ} \mathrm{C}$ the preservation process is still operating at lower maximum temperature and shorter residence times than during conventional heat preservation. Therefore a reduction of the energy requirements from the original $100 \mathrm{~kJ} / \mathrm{kg}$ to $40 \mathrm{~kJ} / \mathrm{kg}$ has been achieved, thus rendering PEF energy efficient and able to be easily integrated in existing food processing operations (Heinz et al., 2002). If a PEF-treatment must be performed strictly at ambient temperature, even the modest heat input will have to be removed by an active cooling system, thus causing additional energy costs. Although possible, cooling systems should be avoided once if cooling is necessary, it means that energy dissipation is too high due to high conductivity, indicating that the product may not be suitable for the PEF process. Despite of the increase of the delivered electrical power, PEF pasteurization seems to be less energy-intensive than traditional pasteurization methods, once it leads to annual savings of 791.2-1055 TJ per year of fossil fuel-equivalents, while also contributing to the reduction of $\mathrm{CO}_{2}$ emissions (Lelieveld, 2005).

HHP processing (100-1000 MPa) is one of the most promising technologies for food treatment and preservation at room temperature (Cheftel, 1992). A popular technique during HHP processing is to combine compression heating with conventional heating for food sterilization (Furukawa, Shimoda, \& Hayakawa, 2003; Koutchma, Guo, Patazca, \& Parisi, 2005). Instantaneous adiabatic compression during pressurization provokes a quick increase in the temperature of the food products, which is reversed when the pressure is released, providing rapid heating and cooling conditions and hence short processing times (Shao, Zhu, Ramaswamy \& Marcotte, 2008). This results in a new approach to food 
sterilization with a significant improvement in the food quality. The combined application of high pressure and heat can be utilized to achieve an inactivation of spores of Clostridium spp. similar to that of conventional sterilization. However, the specific energy input required for sterilization of cans can be reduced from 300 to $270 \mathrm{~kJ} / \mathrm{kg}$ when applying the HHP treatment. In case of HHP processing, a compression energy recovery rate of $50 \%$ can be estimated when a two-vessel system or pressure storage is used. This means that, by making use of energy recovery, a specific energy input of $242 \mathrm{~kJ} / \mathrm{kg}$ will be required for sterilization, corresponding to a reduction of $20 \%$ in the total energy requirements (Toepfl et al., 2006).

Concerning $\mathrm{OH}$, studies conducted at the Agri-Food Canada's Food Research and Development Centre (FRDC) with meat products, where traditional smokehouse cooking was replaced by an ohmic process, indicated that energy savings of at least $70 \%$ could be achieved (Vicente et al., 2006). In tests at the Louisiana State University Agricultural Center, sweet potato samples were processed using $\mathrm{OH}$ prior to freeze-drying. $\mathrm{OH}$ increased the rate of freeze-drying up to $25 \%$, which led to significant savings in both processing time and energy use (Lima, Zhong, \& Lakkakula, 2002; Masanet et al., 2008). Fouling of heat exchangers is an issue for traditional thermal processing systems because it reduces heat transfer efficiency and increases pressure drop affecting the economy of a processing plant (Toyoda, Schreier, \& Fryer, 1994). Fouling-related costs are additional energy, lost productivity, additional equipment, manpower, chemicals, and environmental impact (Gillham, Fryer, Hasting, \& Wilson, 2000). Once surface temperatures are lower in ohmic heating because heat is generated in the bulk fluid, less fouling should take place (Bansal \& Chen, 2006). Despite the lack of information, these novel technologies are also considered locally clean processes (Sun, 2006; Tewari, 2007).

\subsection{Reduced gas and effluent emissions and water savings}

The main types of gas emissions into the air from food processing operations are related with heat and power production and can be summarized as follows:

- Particulate matter and gases, such as carbon dioxide, sulphur dioxide and nitrogen oxides from combustion processes;

- Particulate matter from process operations such as size reduction, cooking and heating processes;

- Volatile organic compounds (VOCs) and other chemicals' emissions from processes involving the heating or cooking of food;

- Halogenated VOCs and other chemicals' emissions leaking from refrigeration systems.

Overall, the traditional preservation by heat is still dependent on temperature-time protocols, and at industrial scale this usually requires large amounts of fossil fuels and water. In fact, it is estimated that in the food industry ca. 57\% of the fossil fuel consumption is used to generate steam (Einstein, Worrell, \& Khrushch, 2001). For example, in 1998, the US food industry accounted for $4.4 \%$ of the energy consumption of the US industry, being the fifth biggest consumer (out of 20 sectors) after petroleum and coal products, chemicals, paper and primary metals (Muller, Marechal, Wolewinski, \& Roux, 2007). At that time, 33\% of the total energy inputs used in food processing corresponded to steam production (see Table 4). Much in the same way, in 2002, the US food industry accounted for $5.4 \%$ of the total purchased energy by the manufacturing sector, and $9 \%$ of the electricity, $9.7 \%$ of the natural gas and $10 \%$ of the coal were used in the food sector (Administration MCES, 2002).

The steam is used for cooking, concentrating liquid foods, drying, and sterilizing, in some food processing facilities. The typical
Table 4

Energy used in US food processing industry (1998).

\begin{tabular}{ll}
\hline End-use consumption & Percent of total energy inputs used \\
\hline Heating & 29 \\
Cooling and refrigeration & 16 \\
Steam production & 33
\end{tabular}

Adapted from Lung et al. (2006).

steam generation method used in food processing facilities implies the use of boilers, where treated cold feed water is fed and receives heat from fuel combustion. Although the feed water is treated, some impurities still remain in it and build up in the boiler. Therefore, a great amount of water is periodically drained from the bottom of the boiler in a process called as blowdown, in order to remove dissolved solids in the boiler system. The blowdown rate for some boilers used in food processing facilities can be as high as $15 \%$ of the steam output, instead of the recommended rate of 1-3\% (Wang, 2009). Insufficient blowdown may lead to the accumulation of dirt and act as an insulator, thus reducing the heat transfer rate and wasting energy. In fact, poor maintenance of boilers can reduce the boiler efficiency up to $20-30 \%$. Boiler efficiency is also affected by heat losses (up to $2 \%$ ) from the boiler surface via radiation and convection. The use of excess of air to burn the fuel is a common practice once it improves safety and reduces NOx emission. However, poorly maintained boilers can have up to $140 \%$ excess air, when $10-15 \%$ excess air is enough. This leads to increased losses of energy and high emissions of $\mathrm{CO}_{2}$. In addition, heat loss through a steam distribution system, which is responsible for carrying the steam from the boiler, is inevitable and if steam lines have leaks, large amounts of steam are lost, which can be a major waste of energy. According to Wang (2009), the energy losses of a steam generation system or boiler could include:

- Flue gas including the sensible heat in the dry flue gas, water vapor formed by the combustion of hydrogen in fuels, and the moisture in fuels and combustion air.

- Boiler blowdown water.

- Incomplete combustion.

- Fouling of heat transfer surfaces.

- Heat convection and radiation losses from the hot boiler surface.

Many efforts have been dedicated to develop a sustainable industry. Reduction of the use of non-renewable energy resources, lower emission of air pollutants such as $\mathrm{CO}_{2}$, and increase of the energy efficiency of devices and processes utilizing renewable energy, is now a major concern for all processors. As shown previously in this text, most of the energy used in the food industry is indirect, and activities such as steam raising account for the biggest share of the combustion process emissions. The combustion processes release a range of pollutants (smoke, carbon dioxide, organic compounds), being these emissions largely dependent on the type of fuel used (Toogood \& Key, 2000). Therefore, food processing systems powered only by electricity may present an environmental advantage when compared with traditional processing technologies. In general, the novel technologies mentioned in Sections 2 and 3 are considered environmental friendly, once they may eliminate completely, or at least reduce significantly the local use of boilers or steam generation systems and consequently, diminish wastewater, increasing water and energy savings. Moreover, if the electricity is generated by an environmentally clean, renewable energy source (e.g. hydroelectric power), then these processes will effectively contribute to reduce the pollution load, helping to preserve the environment. In addition, the novel non-thermal technologies, such as PEF and HHP, may reduce partially the use of cooling 
systems, which often represents approximately $50 \%$ of the total electricity consumption (Dalsgaard \& Abbots, 2003), and are therefore also responsible for pollutant emissions.

Several applications of the so-called novel technologies are still being developed in order to reduce the environmental impact of conventional processes such as peeling, blanching and drying. Conventionally, peeling of fruits and vegetables is performed both by immersion in hot caustic soda solution (lye) or by using steam, which requires high water use and provides less quality. Ohmic peeling reduces environmental problems associated with lye peeling (e.g. treatment of wastewater) because it does not use lye in the process, rather only a very low concentration of $\mathrm{NaCl}$ while yielding a comparable quality of peeled tomatoes (Wongsa-Ngasri, 2004). Mizrahi (1996) reported that blanching by ohmic heating considerably reduced the extent of solid leaching as compared to a hot water process and a short blanching time could be used regardless of the shape and size of the product. E.g. blanching of mushrooms using ohmic heating was recently reported (Sensoy \& Sastry, 2007), being $\mathrm{OH}$ able to maintain a high solids content during the process when compared to conventional blanching, while avoiding the use of excessive amounts of water. It seems clear that $\mathrm{OH}$ blanching offers advantages in terms of water savings without compromising the quality of the processed food.

$\mathrm{OH}, \mathrm{PEF}$, IF and RF can significantly accelerate drying processes when compared to untreated and conventionally heat pre-treated samples (Lima et al., 2002; Nowak \& Lewicki, 2004; Wang, 1995), allowing a precise control of the process temperature and leading to lower energy costs, reduced gas consumption and less combustion-related emissions.

Also the pressure-assisted sterilization processes are the focus of numerous ongoing research projects, once HHP application is considered to be a waste-free process. In fact, the pre-sterilization of packaging by e.g. $\mathrm{H}_{2} \mathrm{O}_{2}$ or other chemical agents will not be required and will therefore contribute to a reduction of the amount of chemicals in the liquid effluents.

\section{Conclusions}

The application of emerging thermal and non-thermal technologies holds potential for producing high-quality and safe food products. Current limitations, related with high investment costs, full control of variables associated with the process operation and lack of regulatory approval have been delaying a wider implementation of these technologies at the industrial scale. It is likely that some of these technologies, according to their specificities, will find niche applications in the food industry (some of them already did), replacing or complementing conventional preservation technologies, through synergistic interactions (e.g. hurdle concept). No matter their state of implementation, it seems clear that emerging thermal and non-thermal technologies have clear environmental benefits, be it by improving the overall energy efficiency of the process or by reducing the use of non-renewable resources.

\section{Acknowledgement}

Author is thankful to the Fundação para a Ciência e Tecnologia (FCT, Portugal) for its Doctoral grant.

\section{References}

Administration Energy information (MCES): Manufacturing energy consumption survey. (2002). <http://www.eia.doe.gov/emeu/mecs/contents.html>.

Ahmed, J., Ramaswamy, H. S., Alli, I., \& Ngadi, M. (2003). Effect of high-pressure on rheological characteristics of liquid egg. Food Science and Technology, 36, 517-524.
Balci, A., \& Wilbey, R. (1999). High pressure processing of milk the first 100 years in the development of a new technology. International Journal of Dairy Technology, 52, 149-155.

Bansal, B., \& Chen, X. (2006). A critical review of milk fouling in heat exchangers Comprehensive Reviews in Food Science and Food Safety, 5, 27-33.

Barbosa-Cánovas, G. V. (2001). Developments in pulsed electric fields - USA research and consortium activities. In Proceedings of electric field processing the potential to make a difference. Chipping Campden: Campden and Chorleywood Food Research Association.

Barbosa-Cánovas, G. V., Palou, E., \& Swanson, B. G. (1997). High hydrostatic pressure food processing. In G. V. Barbosa-Cánovas, U. R. Pathakamury, E. Palou, \& B. G. Swanson (Eds.), Nonthermal preservation of foods (pp. 9-53). New York: Marcel Dekker.

Barbosa-Cánovas, G. V., \& Sepúlveda, D. (2005). Present status and the future of PEF technology. In Gustavo V. Barbosa-Cánovas, María S. Tapia, M. Pilar Cano, Olga Martín-Belloso, \& Antonio Martínez (Eds.), Novel food processing technologies. Boca Raton, USA: CRC Press.

Bengtsson, N., \& Green, W. (1970). Radio-frequency pasteurization of cured hams Journal of Food Science, 35, 681-687.

Bintsis, T., Litopoulou-Tzanetaki, E., \& Robinson, R. (2000). Existing and potential applications of ultraviolet light in the food industry - A critical review. Journal of the Science of Food and Agriculture, 80, 637-645.

Buffler, C. (1993). Microwave cooking and processing: Engineering fundamentals for the food scientist. New York: Van Nostrand Reinhold.

Butz, P., Funtenberger, S., Haberditzl, T., \& Tauscher, B. (1996). High pressure inactivation of Byssochlamys nivea ascospores and other heat resistant moulds. Food Science and Technology, 29, 404-410.

Butz, P., \& Tauscher, B. (2002). Emerging technologies: Chemical aspects. Food Research International, 35, 279-284.

Cheftel, J. C. (1991). Applications des hautes pressions en technologie alimentaire. Industries Agro-Alimentaires, 108, 141-153.

Cheftel, J. C. (1992). Effects of high hydrostatic pressure on food constituents: An overview. In C. Balny, R. Hayashi, K. Heremans, \& P. Masson (Eds.), High pressure and biotechnology (pp. 195-209). London: Colloque INSERM/John Libbey Eurotext, Ltd.

Cheftel, J. C. (1995). Review: High-pressure, microbial inactivation and food preservation. Food Science and Technology International, 1, 75-90.

Cheftel, J. C., \& Culioli, J. (1997). Effects of high pressure on meat: A review. Meat Science, 46, 211-236.

Cho, H., Yousef, A., \& Sastry, S. (1996). Growth kinetics of Lactobacillus acidophilus under ohmic heating. Biotechnology and Bioengineering, 49, 334-340.

Clark, J. (2006). Pulsed electric field processing. Food Technology, 60(1), 66-67.

Craven, H., Swiergon, P., Ng, S., Midgely, J., Versteeg, C., Coventry, M., et al. (2008). Evaluation of pulsed electric field and minimal heat treatments for inactivation of pseudomonads and enhancement of milk shelf-life. Innovative Food Science and Emerging Technologies, 9, 211-216.

Dalsgaard, H., \& Abbots, A. (2003). Improving energy efficiency. In B. Mattson \& U. Sonesson (Eds.), Environmentally-friendly food processing. Boca Raton, USA: CRC Press.

de Alwis, A., \& Fryer, P. (1990). A finite-element analysis of heat generation and transfer during oh of food. Chemical Engineering Science, 45(6), 1547-1559.

de Halleux, D., Piette, G., Buteau, M.-L., \& Dostie, M. (2005). Ohmic cooking of processed meats: Energy evaluation and food safety considerations. Canadian Biosystems Engineering, 47, 3.41-3.47.

Decareau, R. (1985). Pasteurization and sterilization. Microwaves in the food processing industry. Orlando: Academic Press.

Deeth, H., Datta, N., Ross, A., \& Dam, X. (2007). Pulsed electric field technology: Effect on milk and fruit juices. In G. Tewari \& V. Juneja (Eds.), Advances in thermal and non-thermal food preservation. Oxford, UK: Blackwell Publishing.

Einstein, D., Worrell, E., \& Khrushch, M. (2001). Steam systems in industry: Energy use and energy efficiency improvement potentials. Lawrence Berkeley National Laboratory. Available at <http://repositories.cdlib.org/lbnl/LBNL-49081>

Food, for Food Safety and Nutrition, A. (2000). Kinetics of microbial inactivation for alternative food processing technologies: High pressure processing. <http:// www.foodsafety.gov/comm/ift-hpp.html>.

Furukawa, S., Shimoda, M., \& Hayakawa, I. (2003). Mechanism of the inactivation of bacterial spores by reciprocal pressurization treatment. Journal of Applied Microbiology, 94, 836-841.

Galazka, V. B., \& Ledward, D. A. (1995). Developments in high pressure food processing. Food Technology International Europe, 123-125.

Garriga, M., Aymerich, M. T., Costa, S., Monfort, J. M., \& Hugas, M. (2002) Bactericidal synergism through bacteriocins and high pressure in a meat model system during storage. Food Microbiology, 19, 509-518.

Gillham, C., Fryer, P., Hasting, A., \& Wilson, D. (2000). Enhanced cleaning of whey protein soils using pulsed flows. Journal of Food Engineering, 46, 199-209.

Heinz, V., Toepfl, S., \& Knorr, D. (2002). Impact of temperature on lethality and energy efficiency of apple juice pasteurization by pulsed electric fields treatment. Innovative Food Science and Emerging Technologies, 4, 167-175.

Hendrickx, M., Ludikhuyze, L., Van den Broeck, I., \& Weemaes, C. (1998). Effects of high pressure on enzymes related to food quality. Trends in Food Science and Technology, 9(5), 197-203.

Heremans, K. (1995). High pressure effects on biomolecules. In D. A. Ledward, D. E Johnston, R. G. Earnshaw, \& A. P. M. Hastings (Eds.), High pressure processing of foods (pp. 1-197). Nottingham: Nottingham University Press.

Hodgins, A., Mittal, G., \& Griffiths, M. (2002). Pasteurization of fresh orange juice using low-energy pulsed electrical field. Journal of Food Science, 67, 2294-2299. 
Hulsheger, H., \& Niemann, E. (1980). Lethal effects of high-voltage pulses on E. coli k12. Radiation and Environmental Biophysics, 18, 281-288.

Icier, F., \& Ilicali, C. (2005a). The effects of concentration on electrical conductivity of orange juice concentrates during ohmic heating. European Food Research and Technology, 220, 406-414.

Icier, F., \& Ilicali, C. (2005b). Temperature dependent electrical conductivities of fruit purees during ohmic heating. Food Research International, 38, 1135-1142.

Jia, M., Zhang, Q. H., \& Min, D. B. (1999). Pulsed electric field processing effects on flavour compounds and microorganisms of orange juice. Food Chemistry, 65 $445-451$.

Koutchma, T., Guo, B., Patazca, E., \& Parisi, B. (2005). High pressure high temperature sterilization: From kinetic analysis to process verification. Journal of Food Process Engineering, 28, 610-629.

Leadley, C. (2008). Novel commercial preservation methods. In G. Tucker (Ed.) Biodeterioration and preservation. Oxford, UK: Blackwell Publishing Lda.

Leistner, L., \& Gould, G. W. (2002). Hurdle technologies: Combination treatments for food stability, safety and quality. New York: Kluwer Academic/Plenum Publishers.

Lelieveld, H. (2005). PEF-A food industry's view. In Gustavo V. Barbosa-Cánovas María S. Tapia, M. Pilar Cano, Olga Martín-Belloso, \& Antonio Martínez (Eds.) Novel food processing technologies. Boca Raton, USA: CRC Press.

Lima, M., Zhong, T., \& Lakkakula, N.R. (2002). Ohmic heating: A value-added food processing tool. A technical report from Louisiana Agriculture Magazine. Available at: <http://www.Isuagcenter.com/en/communications/publications/ agmag/Archive/2002/Fall/Ohmic+Heating+A+Valueadded+Food+Processing+ Tool.htm>.

Lopez-Fandiño, R., Carrascosa, A., \& Olano, A. (1996). The effects of high pressure on whey protein denaturation and cheese-making properties of raw milk. Journal Dairy Science, 79, 929-936.

Ludikhuyze, L., Van Loey, A., Indrawati, Smout C., \& Hendrickx, M. (2003). Effects of combined pressure and temperature on enzymes related to quality and vegetables: From kinetic information to processing engineering aspects. Critical Reviews in Food Science and Nutrition, 43, 527-586.

Lung, R., Masanet, E., \& McKane, A. (2006). The role of emerging technologies in improving energy efficiency: Examples from the food processing industry. In Proceedings of the Industrial Energy Technologies Conference, New Orleans, Louisiana.

Ma, L., Chang, F., \& Barbosa-Cánovas, G. (1997). Inactivation of E. coli in liquid whole eggs using pulsed electric fields technologies. New frontiers in food engineering. In Proceedings of the Fifth Conference of Food Engineering (pp. 216-221). New York: American Institute of Chemical Engineers.

Marra, F., Lyng, J., Romano, V., \& McKenna, B. (2007). Radio-frequency heating of foodstuff: Solution and validation of a mathematical model. Journal of Food Engineering, 79, 998-1006.

Masanet, E., Worrell, E., Graus, W., \& Galitsky, C. (2008). Energy efficiency improvement and cost saving opportunities for the fruit and vegetable processing industry, an energy star guide for energy and plant managers. Technical report: Environmental Energy Technologies Division <http:// www.energystar.gov/ia/business/industry/Food-Guide.pdf>

McKenna, B., Lyng, J., Brunton, N., \& Shirsat, N. (2006). Advances in radio frequency and ohmic heating of foods. Journal of Food Engineering, 77, 215-229.

Mermelstein, N. H. (1997). High-pressure processing reaches the US Market. Food Technology, 51, 95-96.

Mermelstein, N. H. (1998). Microwave and radiofrequency drying. Food Technology, 52(11), 84-86.

Messens, W., Van Camp, J., \& Huyghebaert, A. (1997). The use of high pressure to modify the functionality of food proteins. Trends in Food Science and Technology, $8,107-112$.

Meyer, R. S., Cooper, K. L., Knorr, D., \& Lelieveld, H. L. M. (2000). High-pressure sterilization of foods. Food Technology, 54, 67-72.

Mizrahi, S. (1996). Leaching of soluble solids during blanching of vegetables by ohmic heating. Journal of Food Engineering, 29, 153-166.

Mozhaev, V. V., Heremans, K., Frank, J., Masson, P., \& Balny, C. (1994). Exploiting the effects of high hydrostatic pressure in biotechnological applications. Trends in Biotechnology, 12, 493-501.

Muller, D., Marechal, F., Wolewinski, T., \& Roux, P. (2007). An energy management method for the food industry. Applied Thermal Engineering, 27, 2677-2686.

Norton, T., \& Sun, D.-W. (2008). Recent advances in the use of high pressure as an effective processing technique in the food industry. Food and Bioprocess Technology, 1, 2-34.

Nowak, D., \& Lewicki, P. P. (2004). Infrared drying of apple slices. Innovative Food Science and Emerging Technologies, 5(3), 353-360.

Palmieri, L., \& Cacace, D. (2005). High intensity pulsed light technology. In Da-Wen Sun (Ed.), Emerging technologies for food processing. New York: Academic Press.

Parrott, D. (1992). Use of ohmic heating for aseptic processing of food particulates Food Technology, 46(12), 68-72.

Patterson, M. F. (2005). Microbiology of pressure-treated foods. Journal of Applied Microbiology, 98, 1400-1409.

Pereira, R., Martins, R., \& Vicente, A. (2008). Goat milk free fatty acids characterization during conventional and ohmic heating pasteurization. Journal of Dairy Science, 91, 2925-2937.

Piyasena, P., Dussault, C., Koutchma, T., Ramaswamy, H., \& Awuah, G. (2003). Radio frequency heating of foods: Principles and applications and related properties - A review. Critical Reviews in Food Science and Nutrition, 43(6), 587-606.

Qin, B., Pothakamury, U., Barbosa-Cánovas, G., \& Swanson, B. (1996). Nonthermal pasteurization of liquid foods using high-intensity pulsed electric fields. Critical Reviews in Food Science and Nutrition, 36(6), 603-627.
Qiu, X., Sharma, S., Tuhela, L., Jia, M., \& Zhang, Q. H. (1998). An integrated PEF pilot plant for continuous non-thermal pasteurization of fresh orange juice. Transactions of ASAE, 41, 1069-1074.

Ramaswamy, R., Balasubramaniam, V., \& Kaletun, G. (2005). High pressure processing: Fact sheet for food processors. Available at: <http://ohioline. osu.edu/fse-fact/pdf/0001.pdf>.

Ramaswamy, R., Balasubramaniam, V., \& Sastry, S. (2005). Ohmic heating of foods. Available at: <http://ohioline.osu.edu/fsefact/0004.html/>.

Resurreccion, A. V. A., Galvez, F. C. F., Fletcher, S. M., \& Misra, S. K. (1995). Consumer attitudes toward irradiated food: Results of a new study. Journal of Food Protection, 58, 193-196.

Rosenberg, U., \& Bögl, W. (1987). Microwave pasteurization, sterilization, blanching and pest control in the food industry. Food Technology, 41(6), 92-99.

Ross, A., Griffiths, M., Mittal, G., \& Deeth, H. (2003). Combining nonthermal technologies to control foodborne microorganisms. International Journal of Food Microbiology, 89, 125-138.

Rowley, A. (2001). Radio frequency heating. In P. Richardson (Ed.), Thermal technologies in food processing. Cambridge, UK: Woodhead Publishing Ltd.

Ryynänen, S. (1995). The electromagnetic properties of food materials: A review of the basic principles. Journal of Food Engineering, 26, 409-429.

Sale, A. J. H., \& Hamilton, W. (1968). Effects of high electric fields on micro organisms iii. Lysis of erythrocytes and protoplasts. Biochimica et Biophysica Acta, 163, 37-43.

Sampedro, F., Rodrigo, M., Martinez, A., Rodrigo, D., \& Barbosa-Cánovas, G. (2005). Quality and safety aspects of PEF application in milk and milk products. Critical Reviews in Food Science and Nutrition, 45, 25-42.

San Martin, M. F., Barbosa-Canovas, G. V., \& Swanson, B. G. (2002). Food processing by high hydrostatic pressure. Critical Reviews in Food Science and Nutrition, 42, 627-645.

Sastry, S., \& Barach, J. (1995). Ohmic and inductive heating. Journal of Food Science, 65(Suppl), 42-46.

Sastry, S., \& Palaniappan, S. (1992). Ohmic heating of liquid-particle mixtures. Food Technology, 46(12), 64-67.

Sensoy, I., \& Sastry, S. (2007). Ohmic blanching of mushrooms. Journal of Food Process Engineering, 27, 1-15.

Shama, G. (1999). Ultraviolet light. In R. K. Robinson, C. Batt, \& P. Patel (Eds.) Encyclopedia of Food Microbiology-3 (pp. 2208-2214). London: Academic Press.

Shao, Y. W., Zhu, S. M., Ramaswamy, H., \& Marcotte, M. (2008). Compression heating and temperature control for high pressure destruction of bacterial spores: An experimental method for kinetics evaluation. Food and Bioprocess Technologies, doi:10.1007/s11947-008-0057-y.

Sitzmann, W. (1995). High-voltage techniques for food preservation. In W. Gould (Ed.), New Methods of Food Preservation. London, UK: Blackie Academic and Professional.

Sun, D.-W. (2006). Thermal food processing: New technologies and quality issues. Boca Raton, USA: Taylor and Francis.

Tewari, G. (2007). High-pressure processing of foods. In G. Tewari \& V. Juneja (Eds.), Advances in thermal and non-thermal food preservation. Oxford, UK: Blackwell Publishing.

Toepfl, S. (2006). Pulsed electric fields (PEF) for permeabilization of cell membranes in food- and bioprocessing-applications. Process and equipment design and cost analysis. PhD Thesis. Berlin.

Toepfl, S., Mathys, A., Heinz, V., \& Knorr, D. (2006). Review: Potential of high hydrostatic pressure and pulsed electric fields for energy efficient and environmentally friendly food processing. Food Reviews International, 22, 405-423.

Toogood, S., \& Key, M. (2000). Air Pollution. In J. M. Dalzell (Ed.), Food industry and the environment in the European Union, practical issues and cost implications (2nd ed.). Gaithersburg, Maryland: Aspen Publishers Inc.

Toyoda, I., Schreier, P., \& Fryer, P. (1994). A computational model for reaction fouling from whey protein solutions. In Proceedings of the fouling and cleaning in food processing conference, Jesus College, Cambridge, 23-25 March.

Vega-Mercado, H., Martin-Belloso, O., Chang, F.-J., Barbosa-Cánovas, G., \& Swanson, B. (1996). Inactivation of Escherichia coli and Bacillus subtilis suspended in pea soup using pulsed electric fields. Journal of Food Processing and Preservation, 20(6), 501510

Vicente, A., \& Castro, I. (2007). Novel thermal processing technologies. In G. Tewari \& V. Juneja (Eds.), Advances in thermal and non-thermal food preservation. Oxford, UK: Blackwell Publishing.

Vicente, A., Teixeira, J., \& Castro, I. (2006). Ohmic heating for food processing. In D. Sun (Ed.), Thermal food processing: New technologies and quality issues. Boca Raton, USA: Taylor and Francis.

Wang, W. C. (1995). Ohmic heating of foods: Physical properties and applications. $\mathrm{PhD}$. dissertation, The Ohio State University, Columbus, $\mathrm{OH}$.

Wang, L. (2009). Energy efficiency and management in food processing facilities. Boca Raton, USA: Taylor and Francis.

Wang, Y., Wig, T., \& Hallberg, L. (2003a). Sterilization of foodstuffs using radio frequency heating. Journal of Food Science, 68, 539-544.

Wang, Y., Wig, T., \& Halleberg, L. (2003b). Dielectric properties of food relevant to rf and microwave pasteurization and sterilization. Journal of Food Engineering, 57, 257-268.

Wongsa-Ngasri, M. S. P. (2004). Ohmic heating of biomaterials: Peeling and effects of rotating electric field. PhD Thesis, Ohio State University.

Zhang, Q., Barbosa-Cánovas, G., \& Swanson, B. (1995). Engineering aspects of pulsed electric field pasteurization. Journal of Food Engineering, 25(2), 261-281.

Zhao, Y. (2006). Radio frequency: Dielectric heating. In D. Sun (Ed.), Thermal food processing: New technologies and quality issues. Boca Raton, USA: Taylor and Francis. 